
Affective-Focused Short-Term Psychotherapy in an Individual With Relational Trauma: The Case of "James"

\title{
Self-Selected Music for Relational Trauma: Commentary on the Psychotherapy Case of "James"
}

\author{
BEN G. ADAMS a,b \\ ${ }^{\text {a }}$ Rawson-Neal Psychiatric Hospital, Las Vegas, Nevada \\ ${ }^{\mathrm{b}}$ Correspondence regarding this article should be sent to Ben G. Adams, Rawson-Neal Psychiatric Hospital, \\ Southern Nevada Adult Mental Health Services-Psychology, Nevada Department of Health and Human Services, \\ Division of Public and Behavioral Health, 1650 Community College Dr., Las Vegas, NV \\ Email: bengadams@caa.columbia.edu \\ Editor's Note: Ben G. Adams is a 2009 PhD graduate of Columbia University Teachers College's Department of \\ Counseling \& Clinical Psychology in New York City. He has broad-based training in clinical psychology, with \\ special interests in posttraumatic stress disorder (PTSD), relational trauma, goals in psychotherapy, and \\ psychological perspectives on creativity and the arts.
}

\begin{abstract}
This commentary discusses Dr. Paul Blimling's (2019) composite case of James, a patient with a history of severe childhood interpersonal trauma, who responded remarkably well to individual psychotherapy augmented with the targeted use of self-selected music. I describe how music and psychotherapy both have their origins in the shamanistic practices of our hunter-gatherer ancestors, such that combining psychotherapy and music together is a reconciliation of sorts. The Case of James demonstrates how music can be used in psychotherapy with a counter-dependent patient, to help the patient to access sensitive, vulnerable feelings that normally would never be expressed to another person. In this case, the therapist's keen sensitivity to the patient's disorganized attachment style created an environment in which the patient eventually felt safe lowering his defenses and expressing his emotions in the treatment—with the help of five songs. Aside from the direct, visceral benefits of the music itself, the process of asking a relationally traumatized patient to select a song has other potential benefits. For example, it supports the patient's sense of self (which, in the relationally traumatized patient, is likely fragmented), and it may reduce the "hot seat" feeling with a self-conscious patient, by shifting focus from the patient to the song. Songs selected by patients in advance of a session versus songs selected during a session may provide different types of information, and may have different types of benefits. If I were working with a patient such as James, two additional possibilities I would consider are (a) helping the patient to develop practical skills for managing overwhelming emotions, and (b) making the patient's goals a more prominent focus throughout the treatment.
\end{abstract}

Keywords: music; psychotherapy; relational trauma; attachment; self-selected songs; case study; clinical case study 
I greatly enjoyed reading both the conceptualization and the case summary of Dr. Paul Blimling's composite case of "James," a patient with a history of severe relational trauma beginning in early childhood, who responded remarkably well to individual psychotherapy augmented with the targeted use of self-selected music.

I particularly enjoyed reading Blimling's literature review, in which he discusses the rationale for introducing self-selected music in individual psychotherapy with a relationally traumatized patient. Blimling makes a compelling case for the idea that music has a special ability to access the unique constellation of affective experience each one of us develops within the context of our earliest interactions with caregivers, regardless of the nature of those interactions.

In this commentary, I will reflect on potential benefits of using self-selected songs in psychotherapy with relationally traumatized individuals. In addition to discussing the value of the music itself, I will discuss other reasons why the use of self-selected songs may be beneficial in psychotherapy with relationally traumatized individuals. I will also discuss the potential relative benefits of using music selected prior to a session versus music selected within a session.

I will also discuss two additional possibilities I would consider if I were providing treatment to a patient such as James, including (a) helping him to develop practical skills for managing overwhelming emotions, and (b) making his goals a more prominent focus throughout the treatment.

\section{MUSIC AND RELATIONAL TRAUMA}

For the relationally traumatized individual who experienced others as unsafe from a very early age, music has the potential to open up the individual to some extremely painful and overwhelming emotions and memories. On the other hand, it is normal for the relationally traumatized individual to have developed strong defenses against experiencing those emotions and memories.

As Blimling demonstrates in the case of James, these defenses are likely to be particularly activated when another person attempts to access those painful emotions and memories within an interpersonal context, given the fact that the trauma itself involves damage to the individual's capacity for adaptive interpersonal experience.

I was very moved by the careful and thoughtful manner in which Blimling introduced music into his work with James. Clearly James was counter-dependent and was going to do everything within his power to avoid bonding with the therapist and opening up his core affects in the presence of another person who-by default_-James viewed as unsafe.

When James did finally lower his defenses with the help of a self-selected song, "Lean on Me," this was an absolutely beautiful moment within the treatment. All the self-protective behaviors James normally engaged in to keep others at a safe distance seemed to be eviscerated for just a brief moment in which he opened up his core emotional experiences in the presence of the therapist, in a refreshingly authentic and vulnerable manner. 
What this moment in the treatment suggests to me is that both music and psychotherapy have the potential to help individuals to access emotions and memories from the past that continue to impact us in the present. When self-selected music and psychotherapy are combined in this way, the result seems almost like a time machine in its potential to bring a person into the thick of developmentally relevant core affective experience.

\section{WHEN MUSIC AND PSYCHOTHERAPY WERE ONE}

On its surface this combining of music and psychotherapy may appear to be an innovation, but it would actually be more accurate to describe it as a reconciliation in the sense that both music and psychotherapy have their historical origins in the ancient forms of psychological healing carried out by shamans in the societies of our hunter-gatherer ancestors (Eliade, 1951/1964; Frank \& Frank, 1993).

In such societies, some of which still exist today in various forms, there is no clear distinction between psychotherapist and musician. Rather, both of these roles are subsumed within the healing practices carried out by shamans. Shamans use music and dance as a way of entering into a trance state in which the shaman embarks on dreamlike metaphysical 'journeys' aimed at healing patient's physical and/or psychological illnesses (Harner, 1980; McClenon, 2001; Moreno, 1995; Wong, 1985).

Historically, shamans were the first music makers in our species (Aigen, 1991; Wong, 1985), such that all the music that has been created by humans since ancient times can be viewed as an evolution of shamanistic practice. This is an idea I proposed in my dissertation on the benefits of using self-selected music and writing to cope with traumatic experiences (Adams, 2009). Specifically, I explored the idea that the popular musicians of our time share many characteristics of shamans in hunter-gatherer societies.

For example, both shamans and contemporary musicians tend to be the exalted deviants of their societies (Hamayon, 1992; Ryan, 1999): Both tend to embrace eccentric and fantastical costume, symbols, and imagery in their work, embracing deviance in a way that tends to be sanctioned and celebrated by the larger culture (Michaelis, 2002, Wong, 1985). Also, both shamans and contemporary musicians function as the storytellers who articulate and express emotions on behalf of their societies (Severi, 2002; Szatmary, 1999; Kraus, 1972, Johnson, 1981).

Another similarly between shamans and contemporary musicians is that both provide wisdom to the societies they serve. Shamans retrieve wisdom through trance and alteration of consciousness, and then share that information with the larger group (Eliade, 1951/1964). Contemporary musicians similarly share wisdom with society, often through insightful song lyrics. Farber (2007) analyzed popular song lyrics from the past several decades and concluded, "there's hardly a worthy topic that rock songs haven't addressed, and sometimes quite wisely" (p. 136). 


\section{SENSITIVITY TO RELATIONAL TRAUMA}

In the case of James, I was impressed that every decision the therapist made as the treatment progressed seemed to be informed by his understanding of James' history of relational trauma and the disorganized attachment style that was associated with it.

I was moved by the degree to which the therapist made it overly clear to James that the therapist was willing and ready to provide a supportive holding space for James, regardless of whatever forms of fleeing, storming, etc., James may have exhibited due to strong counterdependent tendencies.

It requires substantial ego strength to be so facilitating with such a counter-dependent patient, and I was impressed that the therapist didn't do what others may have been tempted to do, that is, roll their eyes and try to get the case assigned to someone else in the clinic.

I thought it was an excellent decision by the therapist to ask James to commit to attending four sessions during the precarious beginning of treatment. This functioned as a clear communication to James that "I want to work with you, I want to help you," and it was a way for the therapist to model vulnerability to James - by communicating that the therapist was open to being rejected by James.

\section{BENEFITS OF SELF-SELECTED MUSIC}

One benefit of using self-selected music in psychotherapy with a relationally traumatized patient is that it serves the important function of supporting the patient's sense of self, which, for a relationally traumatized patient, is likely to be fragmented and fragile. The simple act of asking such a patient to choose a song communicates that the patient's fragmented self, however damaged it may be, is of value, and that the person's feelings are important and deserve to be expressed and validated.

Another potential benefit of using self-selected music in psychotherapy with a relationally traumatized patient is that the content of the music may be useful in helping the therapist to understand the patient's world. A self-selected song can be compared to a dream or a fantasy, in the sense that it provides a distilled thumbnail sketch of the patient's psychological world, including potentially both personal and social aspects.

For a counter-dependent patient such as James, who avoids opening up to the therapist, the patient's personal choice of a song such as "Lean On Me" - which in and of itself speaks volumes about close interpersonal relationships - can make it easier for the therapist to understand how the patient's disorganized attachment style originally formed.

In this sense, use of a self-selected song with a relationally traumatized patient can serve a purpose similar to that of using a board game in psychotherapy with an adolescent: It reduces the patient's vulnerable feeling of being "in the hot seat" and prevents the patient from feeling overly exposed and self-conscious. If the interpersonal realm by its very nature is challenging for 
a patient, it is important for us as therapists to do everything we can to make the therapeutic context feel safe and non-threatening.

In the case of James, by focusing on a song instead of focusing on the patient directly, the therapist made it easier for James to engage in self-expression and self-disclosure within an interpersonal situation that by its very nature arouses the patient's defenses and his tendencies to flee the treatment.

The case of James demonstrates that music can be useful even when it is used sparingly, as it was not used in every session with James. However, each time a self-selected song was used within the treatment, it seemed to serve as a ritual crossing to a new and stronger level in the patient-therapist relationship. In other words, the songs felt like "song events" that in each instance brought the therapeutic relationship to a new and deeper place.

In session 16 James spontaneously brought in a musical recording that was very personally meaningful to him, "American Pie," being related to some highly vulnerable and sensitive feelings. This act by James provided very strong evidence to the therapist that James finally felt safe being vulnerable within the treatment, and that he felt safe exposing his core affective experience in the presence of the therapist.

\section{PRESELECTED MUSIC VERSUS MUSIC SELECTED IN-SESSION}

Reading the case of James led me to reflect on similarities and differences between selfselected music that is preselected (i.e., prior to a session) and self-selected music that is selected spontaneously, within a session.

The case of James shows that both types of self-selected songs can be useful within the context of psychotherapy. Whether a song is selected prior to a session or during the session itself, either way it can potentially serve as "grist for the mill" to help the therapist to better understand the patient.

A preselected song involves more forethought, and is the outcome of a reflective process that in most cases probably occurs across several days. It seems likely that a song selected through this process will be very personally meaningful to the person who chooses it, and will likely provide important basic information about that person's intrapersonal and interpersonal functioning.

A song selected within a session, on the other hand, involves little to no forethought, and is the result of a spontaneous thought process that occurs within the interpersonal context of psychotherapy. Of course, a song selected in this more spontaneous manner may still be very personally meaningful to a patient.

One benefit of asking a patient to select a song within a session is that it gives the therapist an opportunity to access the first song, or one of the first songs, that comes to the patient's mind when asked to choose one. In this sense, a song selected within a session shares some similarity with the psychoanalytic technique of free association. 


\section{MANAGING EMOTIONS}

Any time I hear about a patient with a history of relational trauma, the first thing I think about is whether the patient may benefit from dialectical behavior therapy (DBT; Linehan, 1993; Linehan, 2014). I have found DBT to be very helpful in my own work with relationally traumatized patients, and it is highly popular in our profession for such patients.

I was surprised that the case study of James did not mention the DBT idea of teaching the patient some basic skills for coping with overwhelming emotions. For the most part James seemed to do very well with AEDP psychotherapy combined with self-selected music. I wondered, however, if there might have been some value in adding to the treatment DBT's basic training in coping with challenging emotions.

For example, during sessions 5 to 12 of the treatment, James was reporting an increase in angry outbursts towards others. When I read this, I found myself worrying about the possibility of James either getting into some kind of trouble or further alienating others from him. He seemed to do okay without skills training, but I do think it would have been valuable to at least offer to help James develop some practical skills for managing feelings of anger and frustration.

\section{MAKING GOALS THE FOCUS}

James had a very successful experience in psychotherapy, and was able to accomplish several goals that were important to him. He became more connected to others (by joining a book club and then beginning to date a woman he met there), he maintained his sobriety after a relapse, and he gained some resolution about the death of his sister and his feelings about it. Also, by the end of the treatment he felt less angry and aggressive, and his mood improved substantially.

On the other hand, one thing I personally would have done with James — and it's possible that this happened, but wasn't mentioned in the report - is to make the treatment goals a more prominent focus throughout the therapy. Obviously during the first few sessions the main goal was to prevent James from fleeing the treatment, but once the therapeutic alliance began to form, there may have been some value in speaking more explicitly with James about what specific things he hoped to get out of treatment.

In my first few years as a psychologist I have found myself becoming more focused on goals while working with patients, and have become a strong proponent of solution-focused brief therapy and related modalities. I have found that I can make goals a primary focus even while doing deep emotionally exploratory work with a patient. In my view, goal-setting serves as a reminder to the patient that we are not only working together so the patient has a place to vent and talk about their problems, but also we are working together to improve the patient's life outside of therapy.

For a relationally traumatized patient, focusing on the patient's goals is a way of subtly communicating, "I care about what you want, not about how I think you should be." Also, talking about a relationally traumatized patient's goals throughout the treatment helps to support 
the patient's self-efficacy and sense of self, which is likely to be fragmented. It helps the patient to learn more about their preexisting strengths and to gain a better understanding of how the patient uses those strengths to overcome challenges.

Helping the patient to learn more about how they personally function while pursuing goals empowers the patient to continue to pursue other personal goals after the treatment ends, and increases the likelihood of the treatment serving as a dynamic force for transformation in the patient's life, both during and after treatment.

With relationally traumatized patients who lack confidence and suffer from low selfesteem, I have found it is particularly important to encourage them to celebrate their successes, to give themselves credit for the good things they do for themselves, and to make the "celebration of personal success" an important ongoing aspect of their lives.

In the case of James, the therapist clearly did acknowledge and express appreciation for the remarkable progress James made in the treatment, so I did get the sense that there was a sense of celebration for what James and the therapist achieved together. The only thing I might do differently is to talk more about these gains and to be more deliberate about encouraging James to celebrate them.

\section{REFERENCES}

Adams, B. G. (2009). Coping with traumatic experiences: An analysis of the health benefits of combining music listening with the expressive writing paradigm (Doctoral dissertation). Available from ProQuest Dissertations and Theses Database. (AAT No. 3386109)

Aigen, K. (1991). The voice of the forest: A conception of music for music therapy. Music Therapy, 10, 77-98.

Blimling, G.P. (2019). The effect of integrating music listening with an attachment- and affective-focused short-term psychotherapy in an individual with relational trauma: The case of "James." Pragmatic Case Studies in Psychotherapy 15(2), Article 1, 116-166. Available: http://pcsp.libraries.rutgers.edu

Eliade, M. (1964). Shamanism: Archaic techniques of ecstasy (W. R. Trask, Trans.). Princeton, NJ: Princeton University Press. (Original work published 1951)

Farber, B. A. (2007). Rock 'n' roll wisdom: What psychologically astute lyrics teach about life and love. Westport, CT: Praeger.

Frank, J. D., \& Frank, J. B. (1993). Persuasion \& healing: A comparative study of psychotherapy ( $3^{\text {rd }}$ ed.). Baltimore, MD: Johns Hopkins University Press.

Hamayon, R. N. (1992). Le chamane "joue” et gagne: Ou l'action rituelle champanique, sur la base de materiaux siberiens [The shaman "plays" and profits: Or the shaman's ritual activity, based on Siberian material]. Psychanalystes, 41, 65-78.

Harner, M. (1980). The way of the shaman. San Francisco: Harper.

Johnson, C. L. (1981). Psychoanalysis, shamanism, and cultural phenomena. Journal of the American Academy of Psychoanalysis, 9, 311-318.

Kraus, R. F. (1972). A psychoanalytic interpretation of shamanism. Psychoanalytic Review, 59, 19-32. 
Linehan, M. M. (1993). Cognitive-behavioral treatment of borderline personality disorder. New York, NY: Guilford Press

Linehan, M. M. (2014). DBT Skills Training Manual (2 ${ }^{\text {nd }}$ Ed.). New York, NY: Guilford Press

McClenon, J. (2001). Wondrous healing: Shamanism, human evolution, and origin of religion. DeKalb, IL: Northern Illinois University Press.

Michaelis, D. (2002). Sgt. Pepper's words. The American Scholar, 71, 130-135.

Moreno, J. J. (1995). Ethnomusic therapy: An interdisciplinary approach to music and healing. Arts in Psychotherapy, 22, 329-338.

Ryan, R. E. (1999). The strong eye of shamanism: A journey into the caves of consciousness. Rochester, VT: Inner Traditions.

Severi, C. (2002). Memory, reflexivity and belief: Reflections on the ritual use of language. Social Anthropology, 10, 23-40.

Szatmary, D. P. (1999). Rockin' in time: A social history of rock-and-roll. Upper Saddle River, NJ: Prentice Hall.

Wong, L. T. (1985). Shamanic art in healing rituals. Saybrook Review, 5, 55-63. 